\title{
Design Strategies and Non-Standard Territories. The Resilience of the Domitian Coastline
}

\author{
Giovanni Multari
}

\begin{abstract}
Coastal areas are an extraordinary condition for research and investigation, at a scale encompassing multiple landscapes that underwent a massive transformation, leading to their current crisis state. A landscape with different degrees of depth, with complex conditions and rules of the spatial systems that can be fully understood only through an accurate selection and study of the elements that concurred to its creation. The natural cycle that built the different elements of this landscape is definitely an element to take into account during the definition of the design strategies: through the alluvial deposit first and marine next, it "built" the shore, the dunes - a natural protection against the sea-water level rise and the pinewood behind the dunes. Our goal is strategy that, recovering and recycling the ancient and pre-existing dialogue between the form of the city and the form of the landscape, recovers and recycles that long and natural resilience process: a quality those areas always had, considering also the potential rising of sea levels.
\end{abstract}

Keywords: centuriatio/centuriation, Domitian coastline, resilience

Resilience is a quality that has to be planned for and one that takes time to come to the fore. In the long run, it contributes to the safeguarding of the quality of life and the environment, by means of a balanced use of resources. Therefore, a project must define a strategy capable of strengthening the resilience of territories, cities, and people. The changes of conditions under pressure from the global crisis have led to a senseless exploitation of our territories, leading to poverty, degradation, inequality 
and social exclusion. The effects have hit cities, large urban areas and suburban systems and have not spared the natural landscape and the environment, fundamental resources for human lifecycles and habitats. This crisis is of great environmental impact when "unlimited growth" generates inequalities in the usage and availability of the space. The city and the urban habitat in general are becoming more and more problematic when it comes to safety and climate change-related risks. Whole populations, just like natural systems, are becoming weaker and weaker, and large sections of the territory suffer from structural hazards. For years, the "unlimited growth" attitude has led to constantly pushing the limits and to damage the environmental systems and their ecological components, bearing no consideration whatsoever for the earth's resources. Within certain contexts, such as in Italy and the region around Naples in particular, this attitude has had irreversible consequences on the environment through building and settlement expansion, where growth has degenerated into building speculation, unauthorised constructions, and illegal transformation of the territory. In a short time, this attitude upset the balance among those long-lasting ecological components of the landscape system. In this precarious situation, it is necessary to devise a long-term project that prioritises the collective dimension and the social values of urban space as the lynchpin of change, by means of a project that fully considers the limits of our ecosystem, as well as the times and the effects of its transformation.

\section{DESIGNING RESILIENCE}

Under the circumstances briefly delineated above, space starts to lose its continuity - not only ecological continuity, but also the sign of relations and forms of accessibility that are turned into obstacles: infrastructural, constructive, and managerial barriers that are the hallmarks of a deep and tearing discontinuity. The solution is a strategy that is aware of the system of relations underpinning the social, economic, and environmental components of a territory, and it represents "the new urban question." 1 This implies a return to the definition of a collective dimension, trying to reduce inequalities starting from public space, imagining new forms of cities and housing in the relationships with the landscape and the environment. They have to become "spaces of dwelling," tools for a resilient project that is supported by a great awareness and knowledge of the existing environment, and by the values of a community. Therefore, planning the future means being aware of the material and immaterial consistence of territories and cities, of their potential in transformation, of their ability to introduce actions, and envisioning innovative projects that enhance the performances of existing spaces in terms of quality, development and resilience.

Resilience is the ability of an urban environment to react, regenerate itself, and be sustainable according to a principle that broadens and puts this well-established concept into practice. The pre-condition 
for novel and more adequate forms of transformation for the city and for territories lies undoubtedly in making the cities more resilient and safer. The project transforms itself within the boundaries of a renewed field of action with materials, forms and functions that, compared to traditional practices, acquire a new dimension as bearers of new values, purposes, and objectives. Resilience becomes the goal of the project for public space, gaining importance and relevance in the process of an adaptive development, with a constant evaluation of the possibilities of transformation of its elements and the analysis of its ecologic, economic and urban systems.

Addressing the issues of resilience, climate change, and natural risks through a work on the forms of the landscape and those of the city calls for new materials for a project that cannot be seen as a closed cycle, but rather as an open project. Public space, architecture, and landscape are arranged in a recognisable way, following a strategy that, through a selective design process, encompasses all the available values, keeping an eye on the collective scale of the process.

The complexity of contemporary territories, therefore, demands a paradigm shift in the way we observe and gather information, resulting in articulate responses to the objectives of the investigation and of the strategy to be pursued. The main theme is the enhancement of the relationships among different methods, investigation results, and forms of cities and landscape in order to build a shared knowledge that adopts projects and strategies as tools to design the resilience of these contexts. The definition of new paradigms becomes essential, encompassing the traditional public space and the space of relationship that appears to be characterised by new landscape and environmental formulas. Together with renewed spatial concepts, they contribute to strengthen the idea of a collective and open approach to change and interaction. An active space, more than a representative one, strives to re-naturalize the dwelling space by promoting processes of quality, interaction and integration of the new project that appear well balanced between built spaces and voids. The relationship with the environment triggers the same processes (quality, interaction and relationship) between architecture and landscape, creating an adequate social growth that is aware of the environmental resources. The creation of new networks of active public spaces with eco-efficient solutions in designing and retrofitting what already exists outlines new scenarios for social and cultural gathering. The collective and well-defined public space leaves its place to an open social space for relationships that oppose the urban-territorial project to the comprehensive and closed strategies that led to the crisis and collapse of the systems. The project balances between environment and landscape, it configures the open space beyond scale problems, and stresses the awareness of the meaning and value of resilience to a degree of experimentation on technical research and on potential uses. 
As Carlo Gasparrini has pointed out:

"[This is] the expression of a much deeper need: the proposal for an alternative narration of the city capable of interpreting and representing the dissipative dynamics associated with its metabolism that is opposed to one of the central issues of the urban phenomenon, of its functioning, of its pathologies. It is a narration of the city that chooses to start from the landscape and ecological outcome of those processes, subverting the traditional generalto-particular approach, the systemic comprehensive reading that narrows down to the punctual and definite final impacts on urban spaces." 2

\section{The Domitian Coastline: A Non-Standard Reality}

Analysing the Domitian coastline, north of Naples, Italy, through its settlements and environmental characteristics, means giving recognition to the conditions that governed the form of this territory and implies a necessary definition of the field of operation to identify the relevant questions. The northern coastline of Naples is a sequence of discontinuous settlements and territories alongside the Via Domitiana. ${ }^{3}$ Its study, still today, unveils the original foundational rules of the countryside of Campania (the region around Naples) by the coast, between the natural features of the area and the Roman centuriatio scale. ${ }^{4}$ Today, it can be defined as a non-standard reality, with urban conditions originating from the unlawful town planning of recent years that was perpetrated throughout the entire Campania territory as a result of criminal activities.

Located $45 \mathrm{~km}$ [28 mi.] north of Naples (Fig. 1a), the Pineta Mare district is by far the most famous and most complex among those realities, as it is probably the most resounding unlawful development in Europe. Marked by

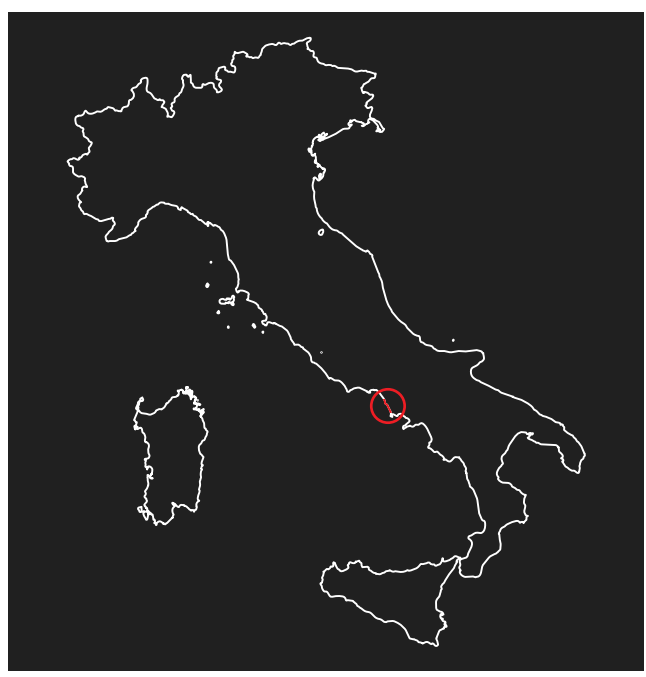

Figure 1a. The study-area on Italy's map.

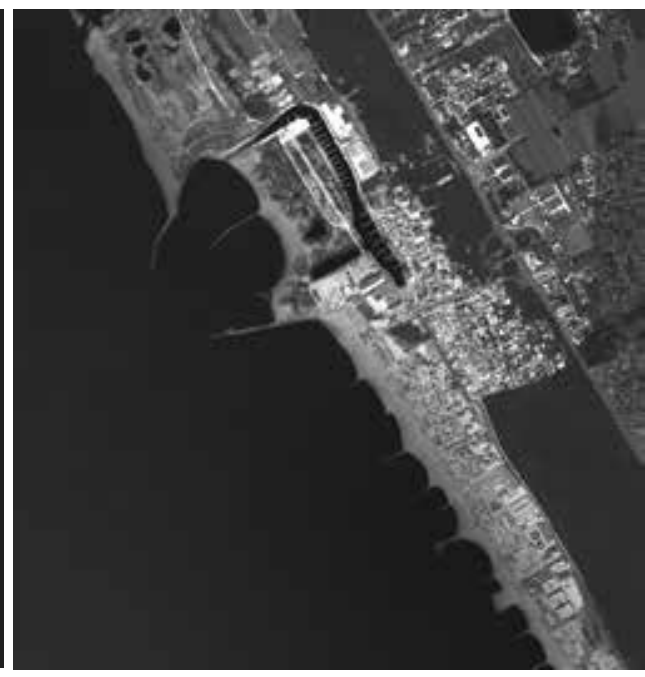

Figure 1b. Aerial survey image of the Campi Flegrei. 
ecological downfall, uncontrolled economic liberalism, organized crime, and immigration, this territory can be considered as a current example of the contemporary urban condition of many world regions. The territory belongs to an area known as Mazzoni, an alluvial plain around the Volturno River that, at the beginning of the seventeenth century, under the supervision of architect Domenico Fontana, witnessed the great reclamation operation encouraged by the Bourbon sovereigns. That operation led to the creation of a significant water drainage network named "Regi Lagni" that still operates today and has a fundamental role for a large area of Campania. This project took into careful account geographical and morphological matters and its reading can become the reference system to define fields, roles, themes, and strategies for transformation. The Regi Lagni are straight channels that collect rain and spring water, draining them from the plain north of Naples down to the sea, between the mouth of the Volturno River and Lake Patria in a large fertile area enclosed northwest by the Campi Flegrei (Fig. 1b).

This drainage network is one of the main patterns that mark the development lines between the coastline and the inner territories. On this system, the manmade elements rooted themselves into the millennial cycle of the creation of the beachside by means of the sediments brought by the rivers, creating the dunes that protect the pinewood - that used to cover the whole coastline - behind them. In the early 1960s, the area around the mouth of the Regi Lagni faced one of the most renowned cases of building speculation, known as "Villaggio Coppola." Its construction began in 1964, when the Castel Volturno municipality granted over 500 building permits. Thousands of other buildings were added over the following twenty years, creating a multi-functional touristic center, inspired by those of the Rimini Riviera on the Adriatic Coast. Villaggio Coppola was built on the stateowned Castel Volturno pinewood, spreading over one million $\mathrm{m}^{2}$ from the late sixties to the eighties. Villaggio Coppola is a broad operation that stretches over four $\mathrm{km}$, where the pinewood and the coast dunes systems stood, meant to become a self-sufficient city only a few minutes away from Naples. The unlawfulness of this large real estate development was already uncovered in the early 1970s, when the Castel Volturno municipality issued several demolition orders that were followed by many legal and judicial actions. The tragic natural events that hit the region in the eighties hindered these legalization initiatives, turning Villaggio Coppola into a shelter for the earthquake-stricken populations.

Over time, this condition brought to an acceptance and recognition of the existing situation. (Fig.2)

Locals are progressively abandoning this wide and dense urban area, which is slowly becoming a place of shelter for the constant Mediterranean migration flows. This complex condition carries contradictions, frictions, unresolved issues, fragmentation and overlapping at the same time, and bears a morphological interest for the reading and study of these areas. 
Today, these places have to be reinterpreted to define a better rule for the spatial and settling systems of the sub-urban informal sprawl. City, landscape and nature are, in this case, the terms to be related and to be interpreted within the different aspects of the project: "a new paradigm [...] a completely different way to look at the residential spaces and their mutation." 5

The project has to examine and select the elements in order to give them a new interpretation and a new scale, to define the place and arrangement of the works of architecture. The new buildings will be able to give a new interpretation to the original landscape and its environmental conditions, giving to the road, the water network, the dunes and the pinewood the role of main register for the arrangement of a text that bears new needs and new necessities.

This strategy assigns to the architectural themes an interpretation of the landscape and its dimension, through the definition of primary roles and functions to be implemented. One of them is the restoration of the urban role of the ancient Via Domitiana that dictates the rules of the already built fabric in a relationship with the broader network of the inland that matches the ancient Roman centuriatio scale.

The reading process brings to the definition of the narrow coastal area, the edge of the vast alluvial plain territories, where the usage of its elements recalls urban characteristics. Their arrangement and the relationships they create, on the other hand, refer to a broader structure, the result of urban sprawl.

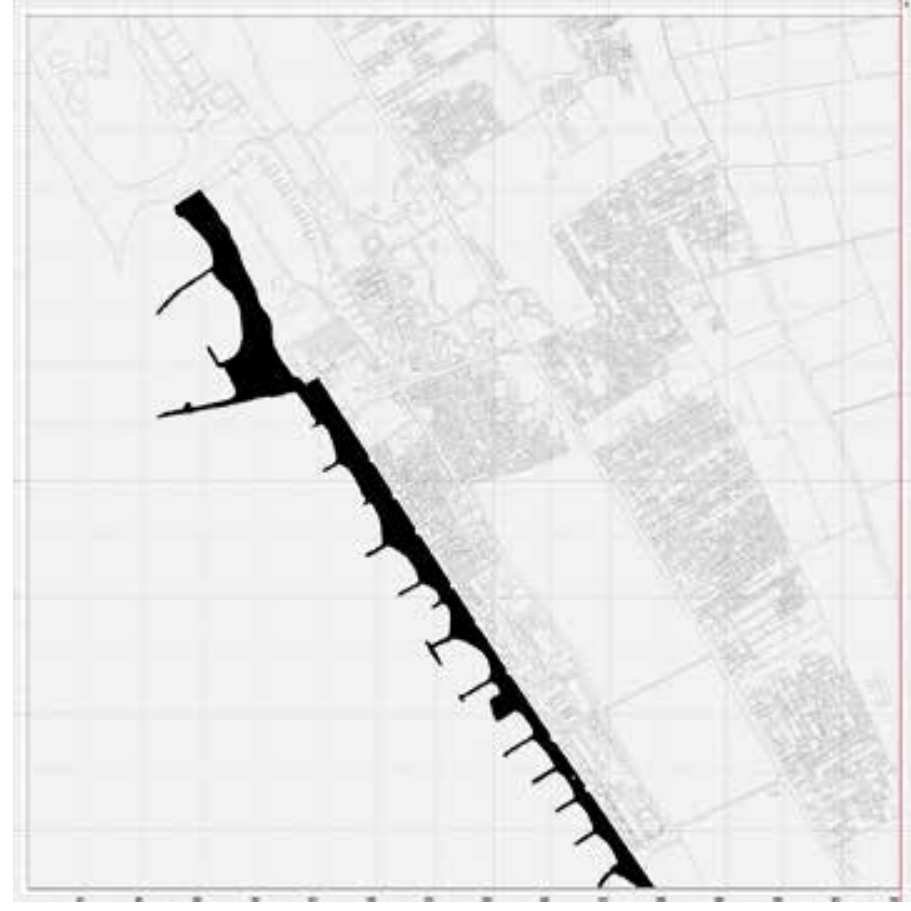

Figure 2a. The beachside.

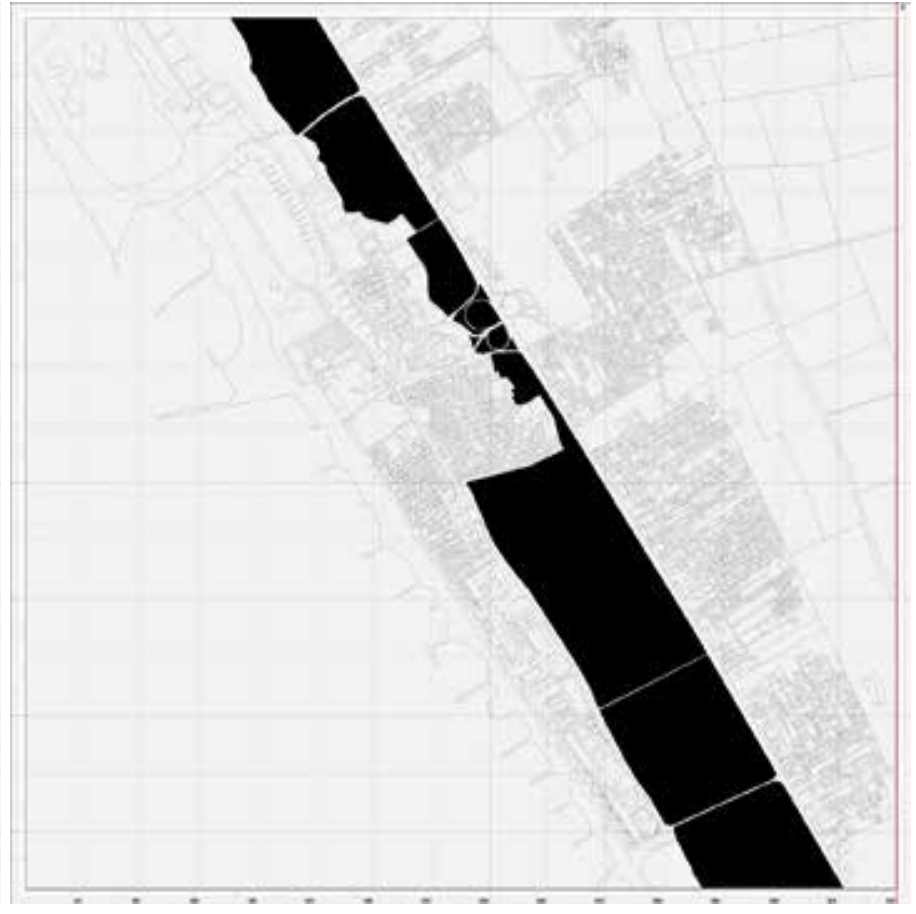

Figure $2 b$. The pinewood. 
The constant accumulation of different systems and logics, usually with a causal connection between them, gives the landscape that sense of left-over space, of casual arrangement, of disorder: characteristics that are often perceived as the expression of the contemporary condition. André Corboz, on choosing this as an aesthetic condition, provides and interesting and useful interpretation: "[...] Unregulated accumulation [...] the result of several choices, all rational or aspiring to be such, that obey to different logics, opposed to one another [...] the chaos is more an order to understand. To get there, we need to investigate more each component, to understand the circumstances that lead to the current state, and make a typical-morphological inventory of the different elements." 6

Understanding a territory such as Castel Volturno implies rebooting the reflection process starting from the morphological reading and the understanding of the landscape, to define and make intelligible the different components that make up the territory. A series of overlapping layers have to be taken into account without prevailing over each other, creating a carefully sorted re-composition operation that can restore the role of the natural systems and tissues through the project interpretation. The elements of this operation require a strong meaning and role, in order to foster a dialogue with the long coastline, the shape of the dunes, the dense pinewood, the ancient Via Domitiana, the water network and the agricultural patterns. This study, and the concept that supports it, are part of the different logics that brought to the definition of the various systems that aim at a simplification of the tools for the project. The consolidated elements

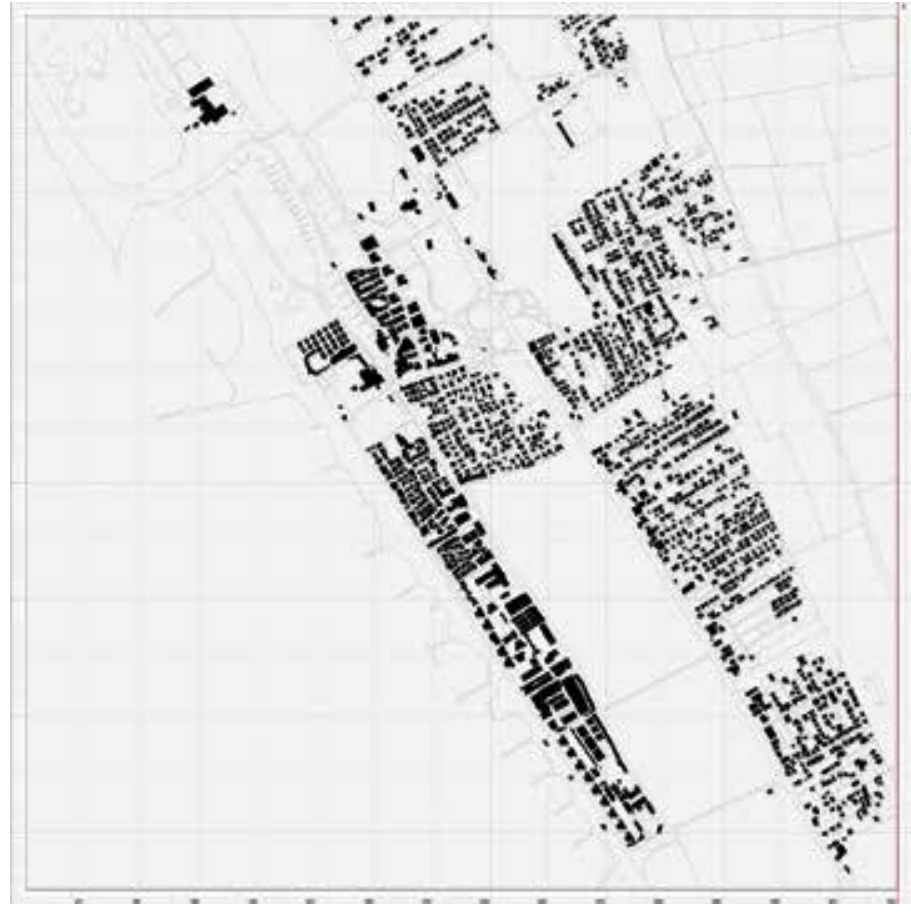

Figure 2c. The built tissue.

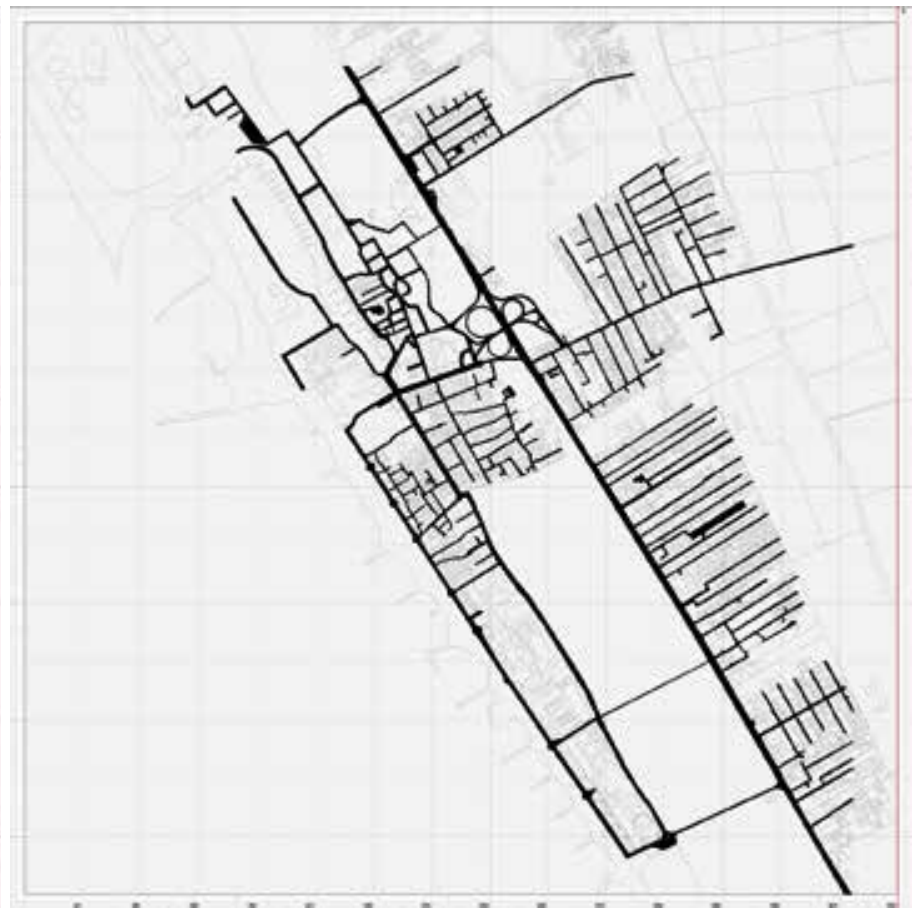

Figure $2 \mathrm{~d}$. The road network 
and the new ones, the routes, and the overlapping tracks are found with these tools, and together create the base for a project to be carried out with a sense of adequacy and recognisability.

\section{Interpreting a Non-Standard Reality}

In the case of Castel Volturno, reading and understanding are a fundamental selective process for those elements that lay the basis for the interpretation process through the project, starting from a landscape still recognizable in some parts, and intact in others.

The physical construction of the urban fabric defined its shape and, in the case of Pineta Mare village, it defies the consolidated rules of urban planning with a layout that obeys mere land use and speculative rules. The theme is how to recompose a fabric with new strategic works of architecture, in a settlement that lacks a logic. This condition complicates the identification of the elements that assign a new role to the areas of intervention, giving a new interpretation to the relationships between the parts, that experiment new orders and hierarchies in the existing tissue. Assigning a theme to this condition is essential for carrying out the project as a strategic action able to confront such a complexity. As philosopher Massimo Cacciari has observed: "the city is everywhere; therefore, there is no more city. We no longer inhabit cities, but territories. The postmetropolitan territory is a geography of events, a practice of connections that go through hybrid landscapes." 7

The dialogue between the form of the city and the form of the landscape needs to be restored via the creation of new development patterns, recognising the value of the contemporary city condition as much more dynamic and subject to more rapid changes compared to the dense, ancient, and stratified city.

The broad network of the contemporary city requires a scale and a role to be assigned to the distances: the residential opportunities, the existing routes, the man-made signs, the overlapping layers: a collection of conditions that point to the choice of themes, such as collective places and open spaces, that become the central point for an adequate strategy of transformation. The project deals with elements and systems to trigger a change - intended as a tool of research and knowledge - in the assignment of a thematic interpretation to such complex territories through the definition of certain figures, landscapes, and reference systems.

The selection of these elements is the key interpretation of the project that implements the residential, spatial, and volumetric aspects that such a theme can express in a peculiar place such as Castel Volturno, according to the significance they are given. Thematic research is essential to the adjustment and the development of the transformations through a system of settlement opportunities for those areas considered as strategic points. This reading leans towards the reality it is oriented to, and finds the answers to its questions in the territories of architecture, to find belonging 
and recognisability again. Therefore, the project finds its roots into the study of nature and its dynamics, and tries to create the conditions for the natural cycle of the coast to continue uninterrupted, providing new spaces and buildings (Fig.3).

A series of simple and light systems that operate on the existing built fabric aims at improving the relations between the pinewood, the residential area and the Via Domitiana. The strategic elements that belong to nature are examined, interpreted and translated into forms of architecture to restore the original function of this strip of land enclosed between the beach and the woods. The creation of new connection elements, new small public spaces along the coastline and the restoration of some abandoned buildings is carried out in a balanced operation that consists of adding new functions and eliminating obstacles. The whole process intends to allow the recreation of the beach-dunes-pinewood system, recreating those longlost connections and relations among these elements. In this way, the new needs can be expressed in a definite context where all choices take into account the different scales and expressions of the territory.

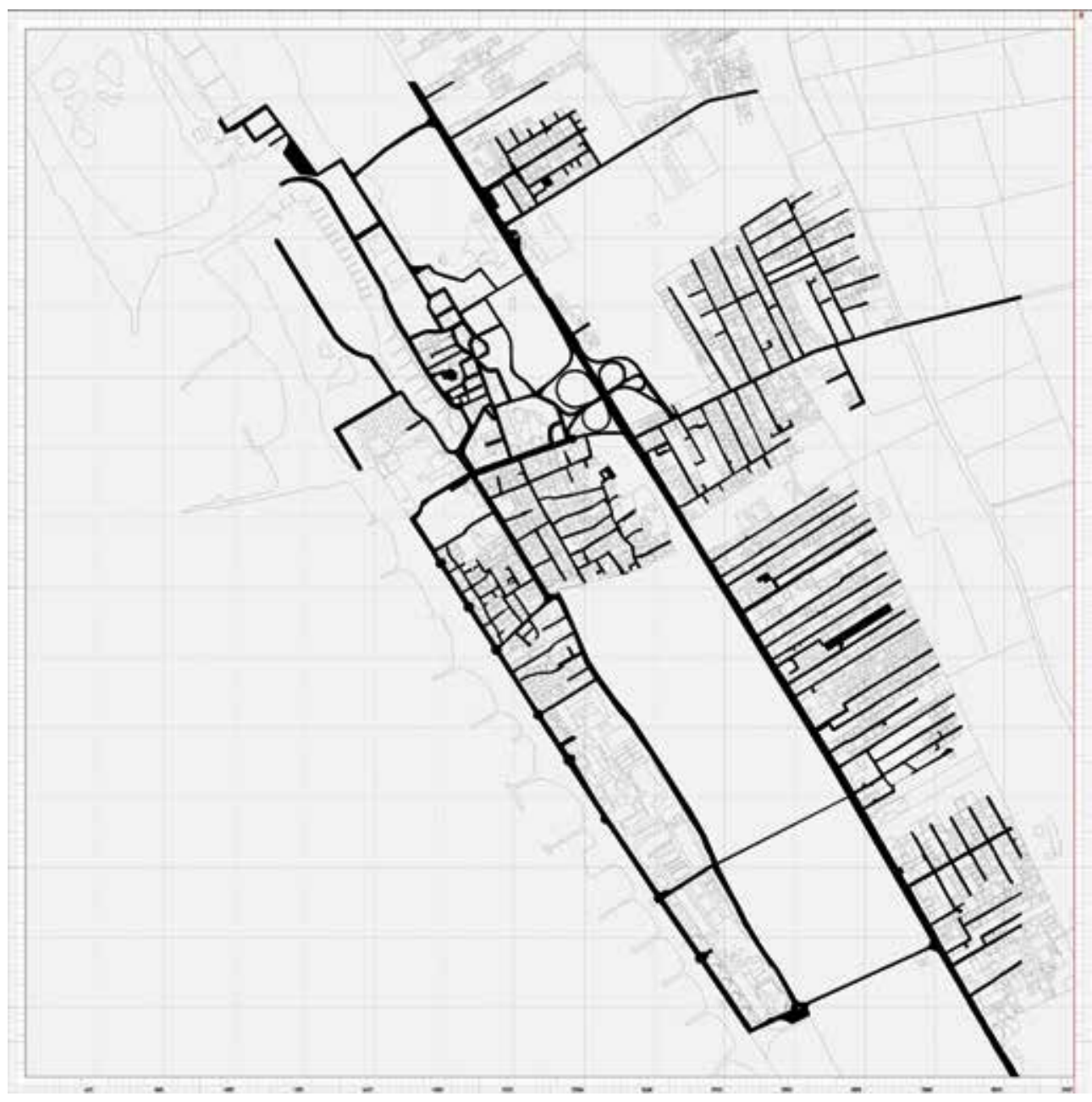

Figure 3a. The connections. 


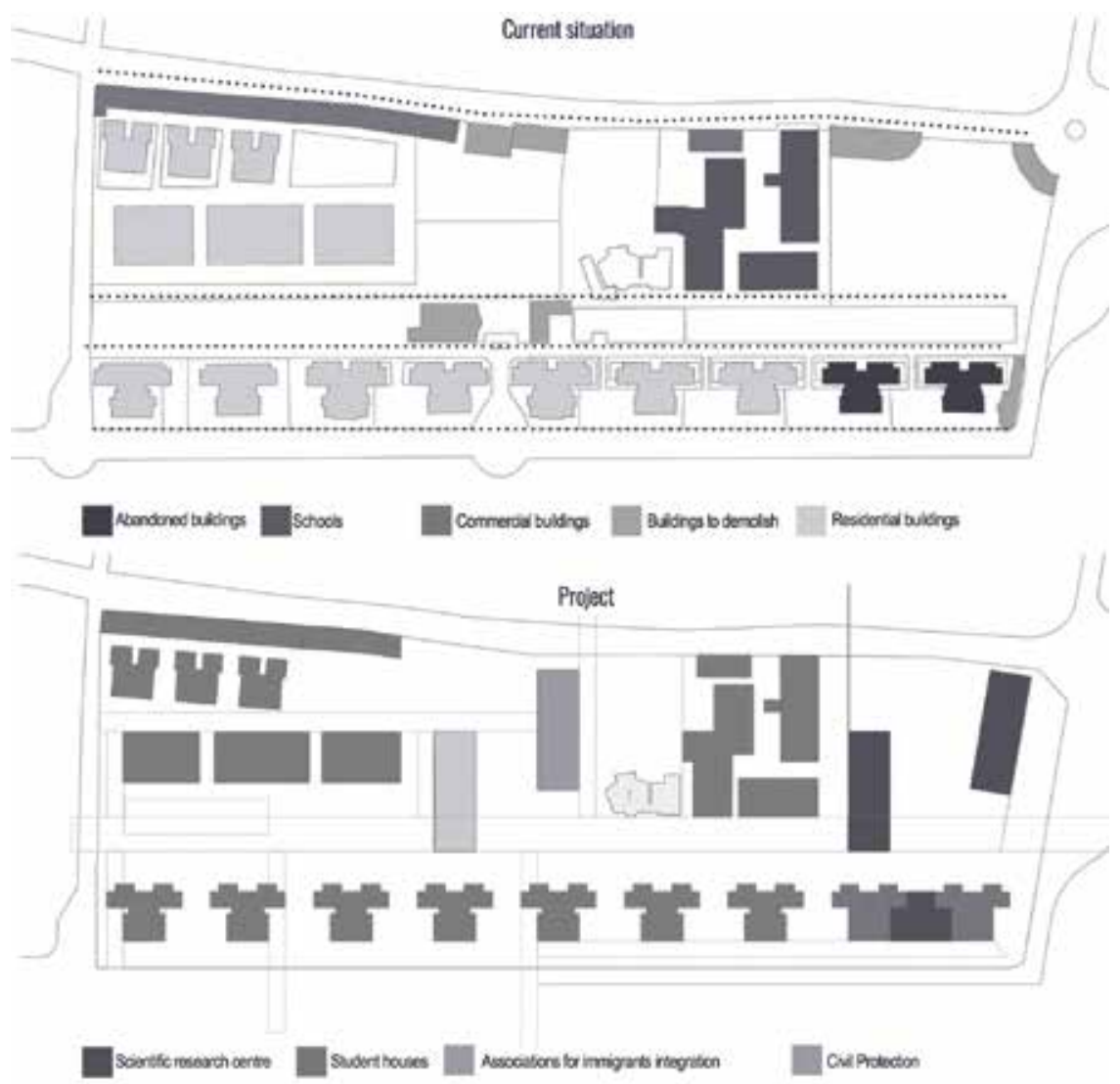

Figure 3b. Functional scheme.
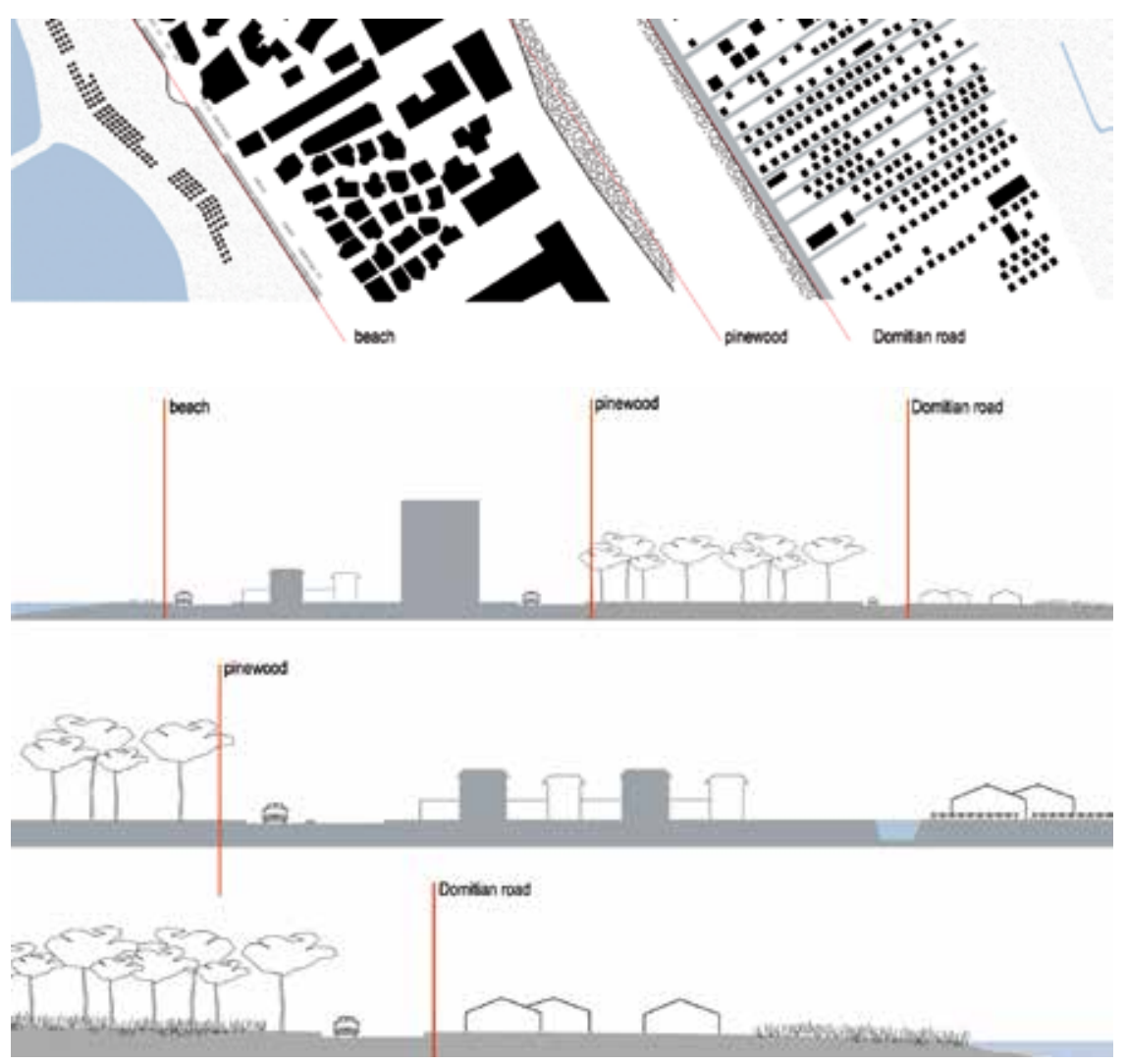

Figure 3c. Sections. 

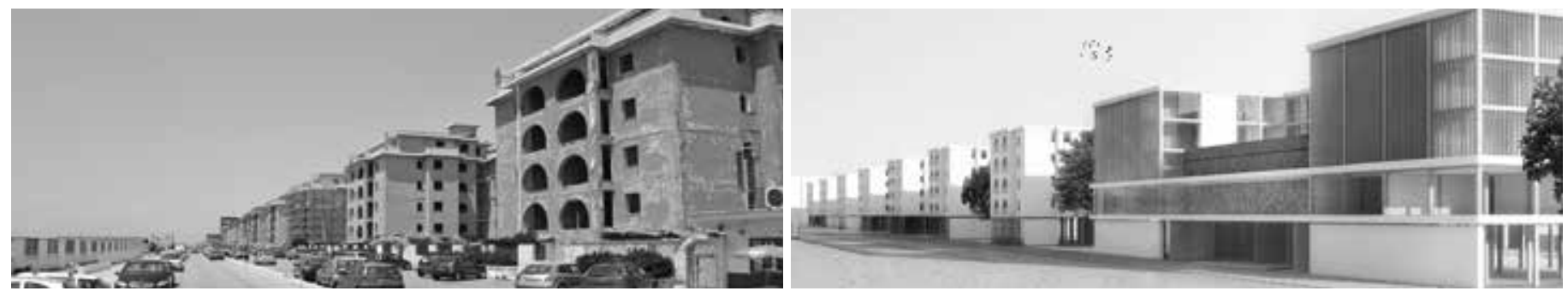

Figure 3d. Studio rendering of the beachfront.

The project establishes a fundamental relationship with the forms of the territory, with its characters and - in the Domitian coastline case - its extraordinary landscape that deserves recognition and interpretation to draw adequate elements capable to have a sense today:

GRID - Manmade landscapes abiding to ancient rules draw attention to the system of routes, streets, natural and artificial water streams, property limits, and crossings that support the different depth of the soil, the beachside, the dunes, the pinewood, the compact built up fabric, and the countryside. A multi-scalar look that overlaps the physical, material, and visible components of the space defining a common ground for the several instances that - in the name of this complexity - can no longer be fragmented. On the contrary, they have to be recognised as forms of the transformation, a necessary resilience as reference and strategy for the project to be adapted and controlled. (Fig. 4)

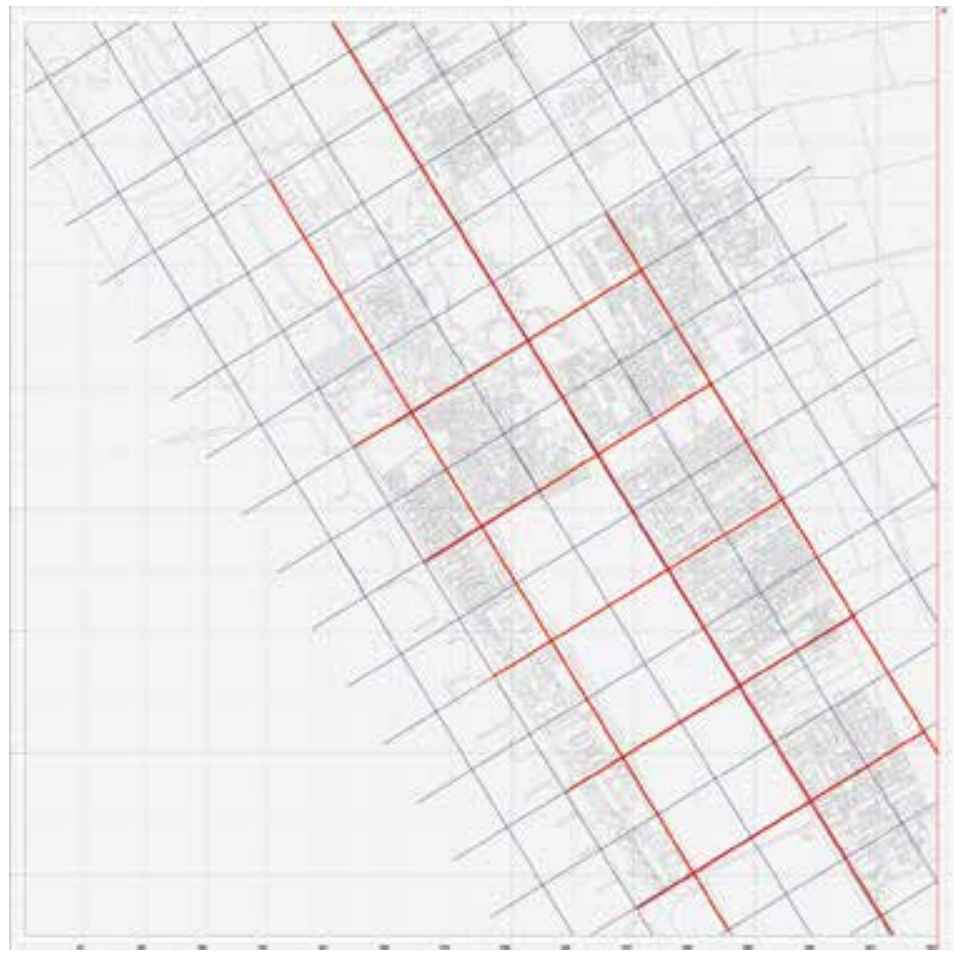

Figure 4.

Multi-scalar vision: the centuriatio grid, modules and sub-modules. 
INTERACTION - The lifecycle of the dunes and the area behind them can be considered as a model of natural balance between the different flows that go through the territory. The landscapes bear the traces of matter and energy flows: they ensure the development of the territories' potential and, at the same time, set out the conditions for their resilience.

An open interaction as balance point, as well as the dune cycle, will enhance the living conditions of the spaces with new meanings, in a system of relations among space, activity, functions and time, (Fig. 5) that take into account the resources, their replicability and their correct usage.
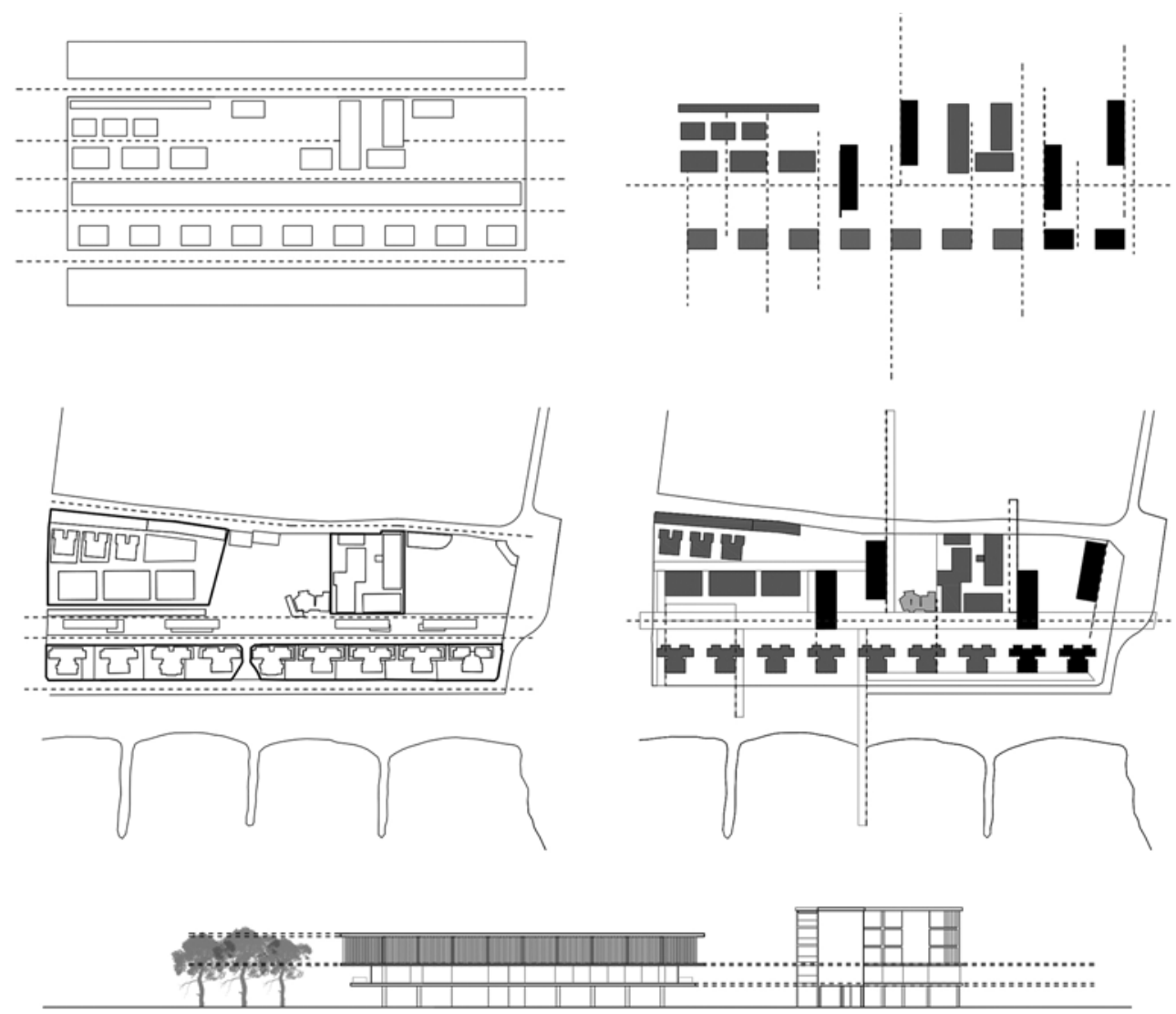

Figure 5. A system of relations among space, activity, functions and time.

RELATIONSHIP - The project has to deal with its participatory and inclusive social role, which should also give importance to local action, instil awareness and give citizens the ability to act, and define its collective dimension. The space of relationship shows new forms (Fig. 6) that enhance its performance in terms of resilience, meaning the ability of that space to resist the general breakdown that our cities and territories are currently experiencing, also from a social point of view. 
RESOURCES - Ecology needs to be the basis for the project and for an efficient use of the resources, just as the lifecycle of the coast that has always ensured and nurtured the entire environmental system. A natural form of recycling that has provided debris, has eroded them, has given them back, and has formed the dunes on which vegetation has grown, protecting the pinewood. A new setup of relations and their dynamics ensuring the logic and the ecology of the project can no longer be considered mere background matters but must be regarded as real assets of the landscape and urban project on mitigation, safety, and resilience (Fig. 7).

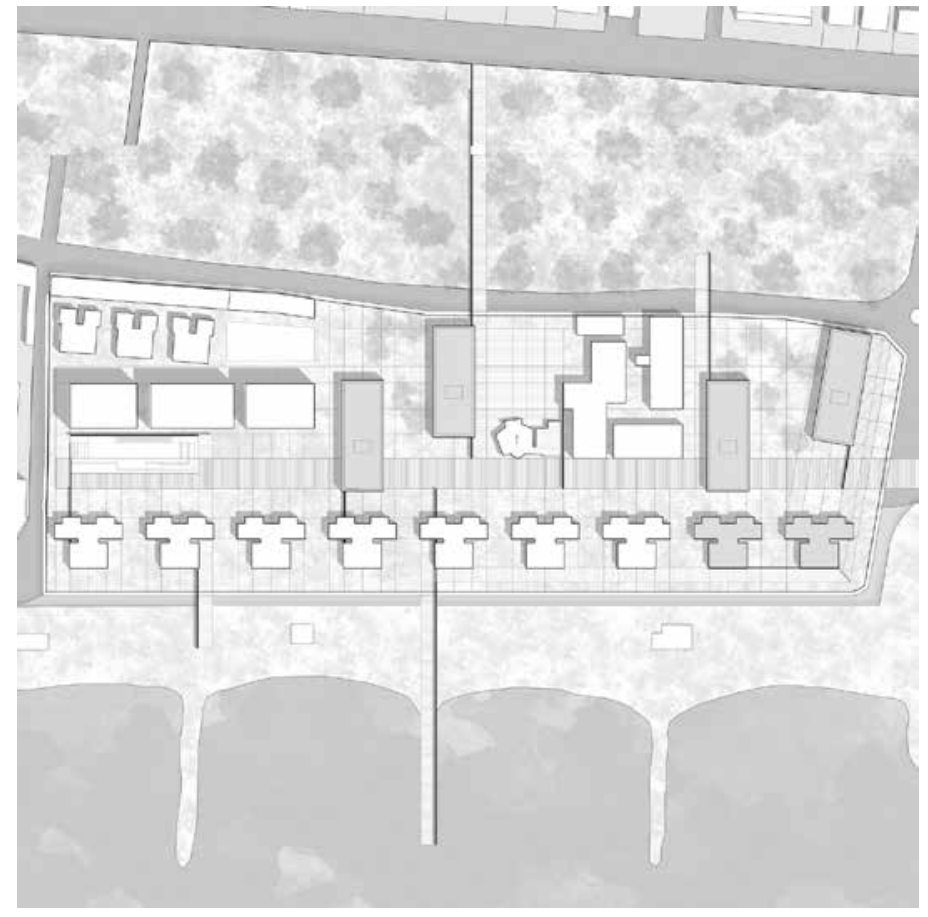

Figure 6. New forms of the space of relations.

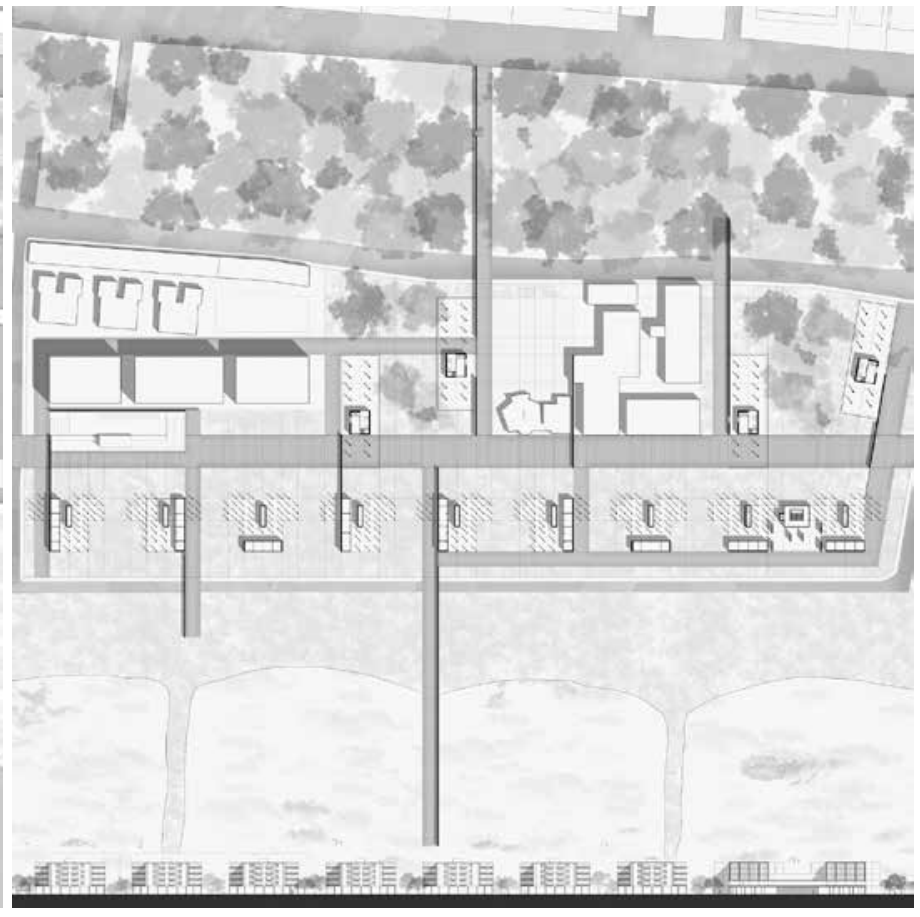

Figure 7. An urban project on mitigation, safety and resilience.

\section{CONCLUSIONS}

The resilience of the Domitian coastline (Fig. 8) lies within the very nature of its formation. Recognising the structure that sustains this territory means evaluating what new actions to implement, to reconvert, recycle, and regenerate all those unlawful actions that brought to the "breakdown" of these territories. Some disastrous actions for the environment and its resources created, in this place, a complex concentration of the results of "unlimited growth," of building speculation operations, and of the effects of waste management and immigration crisis. It is a tangle of problems of our time concentrated alongside very few kilometres of coastline.

The comprehension and recognition of what lies under uncontrolled 
exploitation means bringing back the focus on land use, values and resources for a different and multi-scalar action of the project. If we assume the grid as system of knowledge and structure of the territory, it is necessary to recompose the material and immaterial interactions that have always been present in these areas. With a waterfront that is both natural and urban landscape, the peculiar problems of this territory need to be reconverted with an additive open action in the long run, in order to regenerate that gradual transition from natural environments, open areas and built spaces.

Today's limits are to be overtaken, turning confines, enclosures and compounds into thresholds, crossings, open areas and spaces of relation. This process modifies the contexts gradually, modifies the landscapes and selects - at different scales - the elements of the modification that, as new layers, interact and permeate one another in situations such as this long and often highly stratified part of the coast north of Naples, made of nature, landscape, ancient traces and modern ruins, production, and waste. The beachside and the pinewood, and the alteration of the natural symbiotic process that existed between them, gain a crucial role in giving back a necessary resilience condition to this territory.

In this example of non-standard territory, it is necessary to work on all contexts, to implement all the necessary actions with the purpose of reducing consumption and enhancing safety and awareness. This new system of relations has to build a renewed sense of ethic and an idea of re-composition of the relationship between nature and settlements. As noted by Pino Scaglione: "Landscape and sustainability need to become the public and participated expression of a renewed ethic of living - balancing between nature and city - aimed at improving the human and settling condition [...] able to trigger a path made of new forms for urban and environmental conditions, rich in biodiversity, sustainability, social integration, and diffuse quality." 8

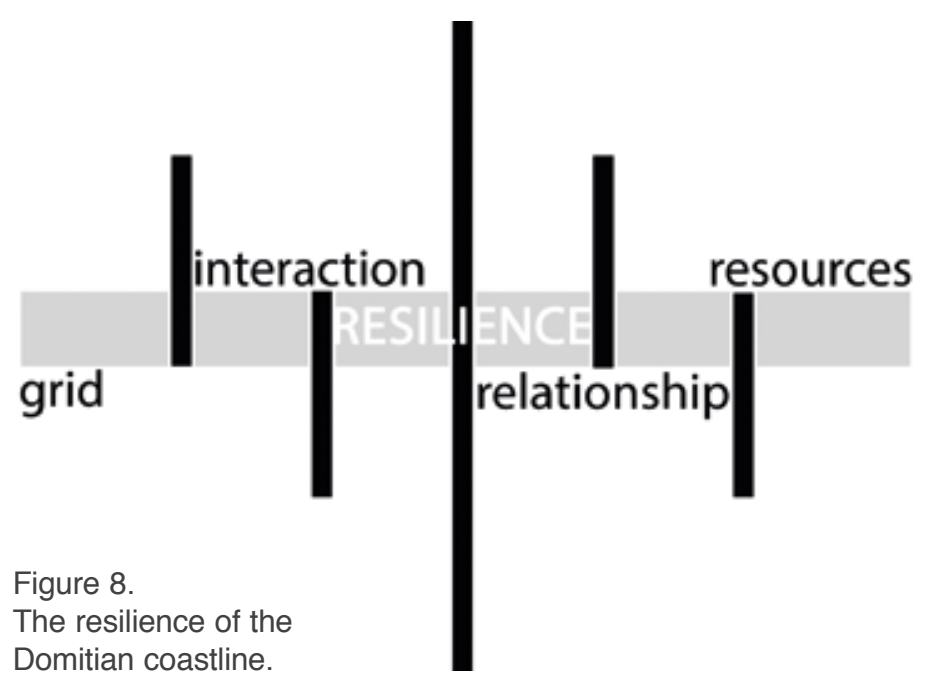




\section{Notes}

1. Bernardo Secchi, "La Nuova Questione Urbana: Ambiente, Mobilità e Disuguaglianze Sociali," Crios, no. 1 (2011): 83-92. doi: https://www.rivisteweb.it/doi/10.7373/70210.

2. Carlo Gasparrini, "Raccontare la Città degli Scarti," in Dross City. Metabolismo Urbano, Resilienza e Progetto di Riciclo dei Drosscape (Trento, It.: List Lab, 2017), 8.

3. The Via Domitiana is a major Roman road built in $95 \mathrm{AD}$ under (and named for) the emperor Domitian to facilitate access to and from the important ports of Puteoli (modern Pozzuoli) and Portus Julius (home port of the western Imperial fleet) in the Gulf of Naples. The road led up the coast and joined the Via Appia (Appian Way) at Formiae (modern Formia). Genseric ultimately destroyed it in 455 AD. [Ed.]

4. The centuriatio (centuriation) was a method of land measurement used by the Romans and it was characterized by the regular layout of a square grid of $710 \mathrm{~m}[2,330 \mathrm{ft}$.] traced using surveyors' instruments. It may appear in the form of roads, canals and agricultural plots. [Ed.]

5. Mosè Ricci, Nuovi Paradigmi (Trento, It.: List Lab, 2012).

6. André Corboz and Bernardo Secchi, Ordine Sparso (Milan: Franco Angeli Editore, 1998)

7. Massimo Cacciari, "Nomadi in Prigione," Casabella, no. 705, November 2002.

8. Pino Scaglione, "Cities in Nature," in Cities in Nature Ecourbanism, Landscape, Architecture (Trento, It.: List Lab, 2012), 53.

\section{Acknowledgments}

This paper comes from the international design workshop organized in Naples by the École nationale supérieure d'architecture Paris-Malaquais (and in particular by Sabine Chardonnet and Carlo Grispello) in November 2015, together with the Department of Architecture (in the person of Giovanni Multari) and the Department of Political Sciences (in the person of Giacomo di Gennaro) of the University of Naples "Federico II." The workshop's name was "Non-Standard Territories. From the usurped waterfront to the hostile neighbourhoods" and it took place in Pineta Mare, Castel Volturno (Italy). The theme of the workshop was further developed during the degree thesis' laboratories within the master's degree course in Architectural Design, DiArc Department of Architecture, University of Naples "Federico II."

\section{Credits}

Figures 1-7: images and drawings by Gennaro Bernardo, Maurizio Calierno, Claudio Savarese.

Figure 8: diagram by the author.

Giovanni Multari is an architect, and he teaches Architectural Design at the Department of Architecture, University of Naples "Federico II," Naples, Italy. In 1995, with Vincenzo Corvino, he founded corvino + multari, based in Naples and with an office in Milan. The Pirelli Tower restoration in Milan awarded the firm the Gold Medal for Italian Architecture and the European Aluminum in Renovation Award. Giovanni was honored the Premio Centocittà and the European Prize "Luigi Cosenza" twice. His latest publications include: The large scale in architecture (Aracne 2015), Resistant Architecture (Aracne 2016), and Corvino+Multari: Architecture experiences (List Lab, 2016).

E-mail: multari@corvinoemultari.com 